\title{
Globally Regionalized Monthly Life Cycle Impact Assessment of Particulate Matter
}

\section{Journal Article}

Author(s):

Oberschelp, Christopher (D); Pfister, Stephan (D); Hellweg, Stefanie (D)

Publication date:

2020-12

Permanent link:

https://doi.org/10.3929/ethz-b-000452729

Rights / license:

In Copyright - Non-Commercial Use Permitted

Originally published in:

Environmental Science \& Technology 54(24), https://doi.org/10.1021/acs.est.0c05691 


\title{
Globally regionalized monthly life cycle impact assessment of particulate matter
}

\author{
Christopher Oberschelp $^{a^{*}}$, Stephan Pfister ${ }^{\mathrm{a}}$, and Stefanie Hellweg ${ }^{\mathrm{a}}$

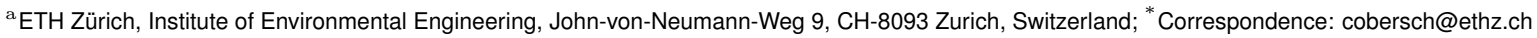

This document represents the accepted version of a manuscript that has been submitted to Environmental Science \& Technology on 26 October 2020. The final version has undergone some minor changes and is available from the publisher at https://dx.doi.org/10.1021/acs. est.0c05691 while the data as well as the source code have been uploaded to http://dx.doi.org/10.17632/8jnj4vzbh6.1.

This work provides a globally regionalized approach for quantifying particulate matter $\left(\mathrm{PM}_{2.5}\right)$ health impacts. Atmospheric transport and pollutant chemistry of primary particulate matter, sulfur dioxide $\left(\mathrm{SO}_{2}\right)$, nitrogen oxide $\left(\mathrm{NO}_{\mathrm{x}}\right)$ and ammonia $\left(\mathrm{NH}_{3}\right)$ from stack emissions were modeled and used to calculate monthly high-resolution maps of global characterization factors that can be used for life cycle impact assessment (LCIA) and risk assessment. These characterization factors are applied to a global data set of coal power emissions. The results show large regional and temporal differences in health impacts per $\mathrm{kg}$ of emission and per amount of coal power generation (5 to $1300 \mathrm{DALY} \mathrm{TWh}^{-1}$ ). While small emission reductions of $\mathrm{PM}_{2.5}$ and $\mathrm{SO}_{2}$ from coal power lead to similar health benefits across densely populated areas of Asia and Europe, we find that larger emission reductions result in up to three times higher health benefits in parts of Asia because of the non-linear health responses to pollution exposure changes. Hence, many regions in Asia benefit disproportionately much from large coal power $\mathrm{PM}_{2.5}$ and $\mathrm{SO}_{2}$ emission reductions. $\mathrm{NO}_{\mathrm{x}}$ emission reductions can lead to equally high health benefits where unfavorable atmospheric conditions coincide with elevated $\mathrm{NH}_{3}$ background pollution and a large amount of population (e.g. in Central Europe, Indonesia or Japan but also numerous other places).

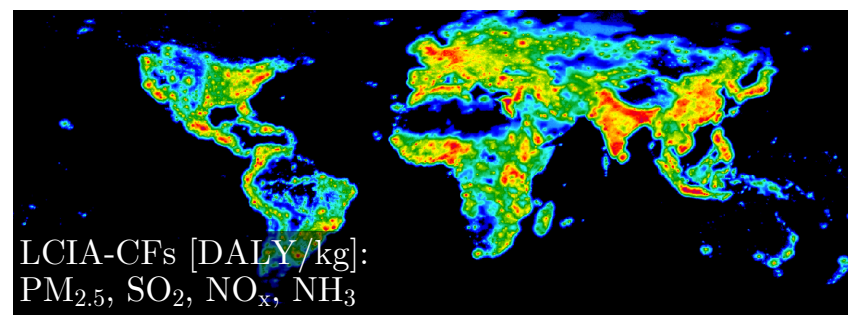

A irborne particulate matter (PM) is the main cause for human deaths and diseases from pollution (1). PM and its precursor substances originate from a multitude of human activities (like fuel combustion or agriculture) as well as from natural processes (like volcano eruptions or deserts). The small fraction of PM with a diameter below $2.5 \mu \mathrm{m}$ (called $\mathrm{PM}_{2.5}$ ) can enter human lungs and cause cardiovascular and respiratory diseases. Life cycle assessment (LCA) aims at quantifying such impacts from different activities and processes to allow for comparisons of products or processes and analyses of hotspots within the life cycle of technical systems.

Several life cycle impact assessment (LCIA) methodologies have been developed to incorporate PM health impacts into
LCA. These methodologies are either country-specific (2-4), based on archetypes (like emission height classes or population density classes) (5-7) or city-specific (8-10). $\mathrm{PM}_{2.5}$ intake in each of these methodologies has been related to health impacts with a simplified linear approach (11) or, more recently, based on non-linear calculations (10). Each of the key parameters in these methodologies (primary pollutants, emission height, population density, atmospheric conditions, background pollution) has decisive influence on health impacts from PM. Thus, spatio-temporal differences in impacts vary over several orders of magnitude (6).

So far, there is no global approach for PM LCIA that includes all the key parameters at high regional and temporal resolution. Thus, the present work aims at providing the first methodology for PM health impact assessment that distinguishes (a) the primary particulate matter $\left(\mathrm{PM}_{2.5}\right)$ as well as secondary $\mathrm{PM}_{2.5}$ from emission of sulfur dioxide $\left(\mathrm{SO}_{2}\right)$, nitrogen oxides $\left(\mathrm{NO}_{\mathrm{x}}\right)$ and ammonia $\left(\mathrm{NH}_{3}\right)$, (b) typical emission source heights, (c) local differences in weather conditions, (d) the time of day, (e) the month of the year, (f) local population densities, $(\mathrm{g})$ the non-linear effects of background pollution on health impacts, and (h) three different types of effect factor models with (i) global coverage. This methodology is applicable to point source emissions and allows for environmental hotspot analysis, source apportionment and quantification of health benefits from emission reduction scenarios.

\section{Materials and methods.}

Characterization factors. Health impact changes integrated over time are approximated in LCA by multiplying emission changes with characterization factors (CFs). CFs for primary and secondary particulate matter in the unit DALY (disabilityadjusted life years) per $\mathrm{kg}$ of emitted pollutant $\mathrm{p}$ were calculated for discrete raster grid cells as shown in equation 1 :

$$
C F_{i, p}=\sum_{j}\left(F F_{i, j, p} \cdot E F_{j}\right)
$$

$\mathrm{FF}$ is the fate factor in units of $\left[\mathrm{kg} \cdot \mathrm{s} / \mathrm{kg} / \mathrm{m}^{3}\right]$ that covers the dispersion and transformation of the air pollutants from each emission source grid cell i to each receptor grid cell $\mathrm{j}$, while EF is the effect factor in [DALY $\cdot \mathrm{m}^{3} / \mathrm{s} / \mathrm{kg}$ ] that covers the exposure, uptake and resulting health impacts of particulate matter in cell $\mathrm{j}$ (all of these variables are also listed in supplementary table 10). This approach for calculating CFs is a different notation of the mathematically equivalent combination of intake fraction $(\mathrm{iF})$, exposure factor $(\mathrm{XF})$ and effect factor (EF) as presented for PM in (5).

We calculated CFs globally at a spatial resolution of $0.25^{\circ} \times 0.25^{\circ}$ (about $25 \mathrm{~km} \times 25 \mathrm{~km}$ at the equator), while the resolution of the receptor grid was $0.1^{\circ} \times 0.1^{\circ}$. CF maps were compiled with emission sources located $2 \mathrm{~m}$ above the ground 
for ground-level, $25 \mathrm{~m}$ for low stack, $100 \mathrm{~m}$ for high stack, $250 \mathrm{~m}$ for very high stack emissions (following the approach from (6)). Annual CF distributions for each grid cell were obtained by performing 500 Monte Carlo runs at random siteand time-dependent weather conditions and background pollution levels. Additional monthly calculations and daytime/ nighttime calculations were performed at a spatial resolution of $1^{\circ} \times 1^{\circ}$ and then spatially disaggregated with the annual data of the respective height class (due to computational limitations). An overview of the approach is shown in the supplementary information (SI) in supplementary figure 1 .

Fate model. Fate factors for equation 1 were calculated as:

$$
F F_{i, j, p}=\frac{\Delta c_{i, j, p}}{\dot{m}_{i, p, e}}
$$

In this equation, $\Delta c_{i, j, p}$ is the $\mathrm{PM}_{2.5}$ ground-level concentration change in $\left[\mathrm{kg} / \mathrm{m}^{3}\right]$ due to an emission rate increase of $\dot{m}_{i, p, e}$ in $[\mathrm{kg} / \mathrm{s}]$. The concentration change $\Delta c_{i, j, p}$ can be obtained from atmospheric transport modeling. Earlier work $(2,12)$ has demonstrated the feasibility of such atmospheric models to calculate the pollutant fate from emission source to human exposure for PM LCIA, but only for a limited amount of large, heterogeneous regions (2) or locally without global coverage (12).

The basis of our fate model was a Gaussian dispersion model, a model class that can be used for approximation of concentrations from individual emission sources up to distances of $500 \mathrm{~km}$ (13). Key characteristics and model equations were directly adapted from existing model implementations $(14,15)$ with the standard model parts (plume rise, stability conditions, ground level concentrations) being explained in more detail in the SI. The following Gaussian equation related the concentration change $\Delta c_{i, j, p}(x)$ of a pollutant $p$ at a location $j$ downwind by distance $x$ in $[\mathrm{m}]$ to a corresponding local downwind pollutant flow rate $\dot{m}_{i, p}(x)[\mathrm{kg} / \mathrm{s}]$ of that pollutant due to an emission at location $i$ :

$$
\Delta c_{i, j, p}(x, y, z)=\frac{\dot{m}_{i, p}(x) \cdot V(x, z)}{2 \pi \cdot v_{\text {wind }} \cdot \sigma_{y}(x) \cdot \sigma_{z}(x)} \cdot \exp \left(\frac{-0.5 \cdot y^{2}}{\sigma_{y}^{2}(x)}\right)
$$

Concentration changes $\Delta c_{i, j, p}$ in $\left[\mathrm{kg} / \mathrm{m}^{3}\right]$ were calculated in the center of each receptor grid cell $j$ with their specific coordinates $(\mathrm{x}, \mathrm{y}, \mathrm{z})$ relative to those of the emission source in the center of cell $i$. The variables in this equation are $\dot{m}_{i, p}$ as local pollutant flow rate change in $[\mathrm{kg} / \mathrm{s}], y$ as crosswind distance in $[\mathrm{m}], z$ as height above the ground in [m], $V$ as the vertical term [-] that accounts for the vertical plume distribution, $v_{\text {wind }}$ as wind speed at the emission source in $[\mathrm{m} / \mathrm{s}], \sigma_{y}$ as the dispersion coefficient in y direction in $[\mathrm{m}]$, and $\sigma_{z}$ as the dispersion coefficient in $\mathrm{z}$ direction in $[\mathrm{m}]$. Directions of $\mathrm{x}$ and $\mathrm{y}$ differed for every Monte Carlo run based on the current wind direction. Equation systems for $V, v_{\text {wind }}, \sigma_{y}$ and $\sigma_{z}$ are presented in the SI.

The chemical conversion of the precursor substances $\mathrm{SO}_{2}$, $\mathrm{NO}_{\mathrm{x}}$, and $\mathrm{NH}_{3}$ to $\mathrm{PM}_{2.5}$ is complex due to the influence of atmospheric conditions and involves several reaction pathways. These pathways as well as reaction kinetics have been adapted from (16-19) and were calculated for each Monte Carlo run based on the specific local atmospheric conditions at the time of emission. Differential equations were set up for the downwind mass flow rate change of each substance $\left(\dot{m}_{i, p}\right)$ at any given time $t$ after emission [s], with $t$ and downwind distance $x$ being related via the wind speed $v_{\text {wind }}[\mathrm{m} / \mathrm{s}]$ :

$$
t=\frac{x}{v_{\text {wind }}}
$$

The solutions of the differential equations were then entered into equation 3 to calculate ground-level $\mathrm{PM}_{2.5}$ concentration patterns from primary $\mathrm{PM}_{2.5}$, as well as $\mathrm{SO}_{2}, \mathrm{NO}_{\mathrm{x}}$ and $\mathrm{NH}_{3}$ as precursors. The differential mass balances for the case of $\mathrm{PM}_{2.5}$ formation from $\mathrm{SO}_{2}$ in the form of ammonium sulfate are presented in equations 5 and $6 . \mathrm{SO}_{2}$ is depleted from the chemical transformation to ammonium sulfate (via sulfuric acid) as well as from wet and dry deposition:

$$
\frac{\partial \dot{m}_{i, S O_{2}}(t)}{\partial t}=-\left(k_{\text {sulf }}+\Lambda_{w, S O_{2}}+\Lambda_{d, S O_{2}}\right) \cdot \dot{m}_{i, S O_{2}}(t)
$$

The reaction rate of $\mathrm{SO}_{2}$ to ammonium sulfate was given as $k_{\text {sulf }}$ in $[1 / \mathrm{s}]$, while $\Lambda_{w, S O_{2}}$ was the wet scavenging ratio $[1 / \mathrm{s}]$ of $\mathrm{SO}_{2}$ due to rain or snowfall and $\Lambda_{d, \mathrm{SO}_{2}}$ was the average dry scavenging ratio $[1 / \mathrm{s}]$ of $\mathrm{SO}_{2}$ due to dry deposition.

The mass balance for the amount of ammonium sulfate ( $\left.\dot{m}_{i \text {,sulf }}\right)$ covered its formation from $\mathrm{SO}_{2}$ as initial educt as well as its depletion from wet and dry deposition:

$$
\begin{aligned}
\frac{\partial \dot{m}_{i, \text { sulf }}(t)}{\partial t}= & k_{\text {sulf }} \cdot \dot{m}_{i, S O_{2}}(t) \cdot \frac{M_{\text {sulf }}}{M_{S O_{2}}} \\
& -\left(\Lambda_{d, \text { sulf }}+\Lambda_{w, \text { sulf }}\right) \cdot \dot{m}_{i, \text { sulf }}(t)
\end{aligned}
$$

Here, $M_{\text {sulf }}$ and $M_{\mathrm{SO}_{2}}$ were the molar masses of ammonium sulfate and $\mathrm{SO}_{2}[\mathrm{~kg} / \mathrm{kmol}]$, respectively, whereas $\Lambda_{w \text {, sulf }}$ was the wet scavenging ratio $[1 / \mathrm{s}]$ of ammonium sulfate and $\Lambda_{d \text {,sulf }}$ the average dry scavenging ratio $[1 / \mathrm{s}]$ of ammonium sulfate. Wet and dry scavenging ratios were each approximated in every Monte Carlo run as not being a function of downwind distance $x$ so that an analytical solution to the differential mass balances would exist. Thus, the two differential mass balances 5 and 6 could be solved for $\dot{m}_{i \text {,sulf }}$ :

$$
\begin{aligned}
\dot{m}_{i, \text { sulf }}(t)= & \frac{M_{\text {sulf }}}{M_{S O_{2}}} \cdot \dot{m}_{i, S O_{2}, e} \cdot k_{\text {sulf }} \cdot\left(-k_{\text {sulf }}\right. \\
& \left.-\Lambda_{d, S O_{2}}-\Lambda_{w, S O_{2}}+\Lambda_{d, \text { sulf }}+\Lambda_{w, \text { sulf }}\right)^{-1} \\
& \cdot\left[\exp \left(-\left(k_{\text {sulf }}+\Lambda_{d, S O_{2}}+\Lambda_{w, S O_{2}}\right) \cdot t\right)\right. \\
& \left.-\exp \left(-\left(\Lambda_{d, \text { sulf }}+\Lambda_{w, \text { sulf }}\right) \cdot t\right)\right]
\end{aligned}
$$

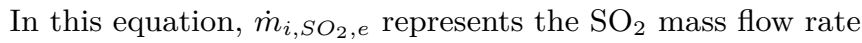
change of the emission source in $[\mathrm{kg} / \mathrm{s}] . \mathrm{SO}_{2}$ reacts to ammonium sulfate via the formation of sulfuric acid as an intermediate product. The reaction from sulfuric acid to ammonium sulfate has been assumed to be instantaneous based on (18) and sufficient ammonia concentrations were assumed to be generally available based on (20). Ammonium sulfate was assumed to be $100 \% \mathrm{PM}_{2.5}(20)$.

The model for wet deposition, the washout of pollutants with rain or snow, was adapted from (17). Dry deposition, the settling of substances due to gravitational and other forces during dry conditions, was calculated based on surface concentrations. Both models are explained in the SI.

The formation of $\mathrm{PM}_{2.5}$ from $\mathrm{NO}_{\mathrm{x}}$ and $\mathrm{NH}_{3}$ was modeled similarly as for $\mathrm{SO}_{2}$, but involved an additional reversible chemical equilibrium that occurred simultaneously as the wet and dry deposition. Calculating these effects side by side would have required solving a computationally costly volume integral. 
Thus, we approximated this by calculating the educt amounts after wet and dry deposition first. In a second step, we then calculated the ground-level $\mathrm{PM}_{2.5}$ concentrations from the chemical equilibrium. The equilibrium chemistry was based on the approaches of $(16,18,19)$ (details in the SI).

For the Gaussian atmospheric model, a cut-off is applied at $250 \mathrm{~km}$ because of calculation time. The remaining share of the impact was then approximated with the fate model results from (5) and average EFs applied to the remaining fraction of PM and precursors at the $250 \mathrm{~km}$ cut-off. Thus, we extended equation 1 accordingly:

$$
C F_{i, p}=\sum_{j}\left(F F_{i, j, p} \cdot E F_{j}\right)+F F_{i,>250, p} \cdot \overline{E F}_{>250}
$$

In this equation, $F F_{i,>250, p}$ is the fate factor outside the cut-off per pollutant $p$ in $\left[\mathrm{kg} \cdot \mathrm{s} / \mathrm{kg} / \mathrm{m}^{3}\right]$. The global populationweighted average effect factor $\overline{E F}_{>250}$ in $\left[\mathrm{DALY} \cdot \mathrm{m}^{3} / \mathrm{kg} / \mathrm{s}\right.$ ] was calculated for 143.9 million people in the cut-off area (based on the global average population density (21) and the cut-off dimensions according to (5)) as described below. The cut-off fate factor $F F_{i,>250, p}$ was calculated as:

$$
F F_{i,>250, p}=\frac{w_{>250, p} \cdot i F_{p, \text { cut-off }}}{B R \cdot \bar{n}_{\mathrm{pop}, \mathrm{cut}-\mathrm{off}}}
$$

The precursor mass fraction that remained in the air at the cut-off in $[\mathrm{kg} / \mathrm{kg}]$ is $w_{>250, p}$, while $i F_{p \text {,cut-off }}$ is the average rural intake fraction per pollutant from (5), $B R$ the human breathing rate of $13 \mathrm{~m}^{3} \mathrm{~d}^{-1}$ from (5) and $\bar{n}_{\text {pop,cut-off the corre- }}$ sponding average amount of exposed people. The remaining mass fraction of the pollutants at the cut-off location was calculated with the results from mass balances. Reaction intermediates that had not yet transformed to $\mathrm{PM}_{2.5}$ at the cut-off distance were added to their corresponding precursor mass fractions because there were no specific iFs available for intermediates.

Simplifications concerning reaction pathways, plume rise and other effects implied in any of the equations above are explained and discussed in the SI.

Effect factor model. In the existing research of PM LCIA, three types of effect factor models are employed: marginal, average, and linear $(22,23)$. The marginal EF represents the change of impact per change of emission for an infinitesimal emission change. It is particularly useful for approximating effects of small emission changes. The average effect model, in contrast, represents the average change of impact per change of emission for concentrations above a certain baseline concentration as a desirable target condition. This baseline concentration is often set to the no-effect concentration of $\mathrm{PM}_{2.5}$, the background $\mathrm{PM}_{2.5}$ concentration below which no contribution to health impacts from $\mathrm{PM}_{2.5}$ exposure is observed. It may be used for approximating average effects of larger emission changes (depending on the choice of the baseline concentration). The linear effect model, finally, is a specific average effect model where the baseline background concentration is set to zero and thus may quantify the average change of impact per change of emission for concentrations above zero concentration of $\mathrm{PM}_{2.5}$. Each of these three different types of EFs were calculated as adaptations of the approaches from $(10,11,24)$. The inherent non-linearities of these three approaches present a challenge for the resulting CF because of their steep slope at low, commonly encountered PM background concentrations. Thus, local EFs and hence CFs are extremely sensitive towards fixed $\mathrm{PM}_{2.5}$ background concentrations. PM background concentrations, however, fluctuate heavily over time, so we used distributions for the PM background concentrations rather than fixed PM background concentrations (details in the SI).

Regional differences in PM EFs do not only arise from background concentrations, but also from regional susceptibility to PM impacts. We calculated global average EF functions based on global average health burdens and life expectancies:

$$
\dot{H} I_{k, j} \approx \frac{n_{\mathrm{pop}, j}}{n_{\mathrm{pop}, \text { global }}} \cdot \dot{H} I_{\mathrm{k}, \text { global }}
$$

In this equation, $\dot{H} I$ is the annual health impact for each PMrelated disease $k$ in [DALY $/ \mathrm{yr}]$ as obtained from (1), $n_{\mathrm{pop}, j}$ the exposed population in receptor grid cell $j$ and $n_{\text {pop,global }}$ the total global population from (21). As several causes can lead to the same diseases, the share that can be attributed to $\mathrm{PM}_{2.5}$ exposure concentration $c$ in $\left[\mathrm{kg} / \mathrm{m}^{3}\right]$ had to be calculated. This approach has been demonstrated in (24). Thus, the attributable fraction $A F$ was used:

$$
\dot{H} I_{k, j, P M}(c)=A F_{k, P M}(c) \cdot \dot{H} I_{k, j}
$$

The attributable fraction [DALY/DALY], in turn, was calculated from the disease- and age-specific relative risk $R R$ (also known as risk ratio), which is defined as incidence rate of an exposed group divided by the incidence rate of an unexposed group of people:

$$
A F_{k, P M}(c)=1-\frac{1}{R R_{k, P M}(c)}
$$

The relative risk functions have been developed by a fit to PM health impact cohort study data by (24) and were widely used by the Global Burden of Disease studies (1). Their applicability to PM LCIA have been discussed and demonstrated before by (10). Marginal effect factors $E F_{j, \operatorname{marg}}$ in $\left[\mathrm{DALY} \cdot \mathrm{m}^{3} / \mathrm{s} / \mathrm{kg}\right.$ ] for each receptor grid cell $j$ with a background $\mathrm{PM}_{2.5}$ concentration $c_{b g, P M, j}$ in $\left[\mathrm{kg} / \mathrm{m}^{3}\right]$ were defined as:

$$
E F_{j, \operatorname{marg}}:=\left.\sum_{k} \frac{\partial \dot{H} I_{k, j, P M}(c)}{\partial c}\right|_{c=c_{b g, P M, j}}
$$

Thus, they were directly calculated as:

$$
\begin{aligned}
E F_{j, \operatorname{marg}}= & \sum_{k}\left(\dot{H} I_{k, j} \cdot \frac{1}{R R_{k, P M}^{2}\left(c_{b g, P M, j}\right)}\right. \\
& \left.\left.\cdot \frac{\partial R R_{k, P M}(c)}{\partial c}\right|_{c=c_{b g, P M, j}}\right)
\end{aligned}
$$

Average effect factors $E F_{j \text {,avg }}$, instead, were defined as

$$
E F_{j, \text { avg }}:=\sum_{k} \frac{\Delta \dot{H} I_{k, j, P M}(c)}{\Delta c}
$$

and could then be calculated by inserting equations 11 and 12 (further explanations are provided in the section Average and linear effect factors of the SI):

$$
\begin{aligned}
E F_{j, \text { avg }} \approx & \sum_{k}\left(\dot { H } I _ { k , j } \cdot \left(\frac{1}{R R_{k, P M}\left(c_{2}\right)}\right.\right. \\
& \left.\left.-\frac{1}{R R_{k, P M}\left(c_{1}\right)}\right) \cdot \frac{1}{c_{1}-c_{2}}\right)
\end{aligned}
$$


In the latter case, $c_{1}$ was the $\mathrm{PM}_{2.5}$ background concentration of cell $j\left[\mathrm{~kg} / \mathrm{m}^{3}\right]$ while $c_{2}$ was the minimal no-effect concentration as obtained from the data in (10). Linear EFs between the current $\mathrm{PM}_{2.5}$ exposure in cell $j$ and zero $\mathrm{PM}_{2.5}$ exposure were finally calculated like average EFs by setting $c_{2}$ to zero, while keeping $c_{1}$ as the $\mathrm{PM}_{2.5}$ background concentration of cell $j$.

Input data. Monthly gridded weather data (minimal, mean and maximal temperatures, and precipitation amounts) has been obtained from (25). Relative air humidity data was used from (26), while 2015 monthly cloud cover data was used from (27). Monthly precipitation frequency data was available from (28). Wind speed frequency and direction data was obtained from (29). Background pollution maps were used from (30-33) and ground-level pollution measurement data from (34-42). Spatio-temporal distributions of atmospheric conditions were derived from these data sources as detailed in the SI.

Emission flow rates for the different height classes (groundlevel, low stack, high stack, very high stack) were assumed to be $0.001 \mathrm{~kg} \mathrm{~s}^{-1}, 0.01 \mathrm{~kg} \mathrm{~s}^{-1}, 0.1 \mathrm{~kg} \mathrm{~s}^{-1}$ and $1 \mathrm{~kg} \mathrm{~s}^{-1}$, respectively. These emission rates each loosely correspond to emissions of diesel generators, ship engines, modern coal power plants, and outdated coal power plants.

Spatially distributed population density data for 2015 has been taken from (43). Classification into urban and rural regions was available from (44). Country and region polygons from (44), ecoinvent v3.6 region polygons from (45), ecoinvent v3.7 region polygons from (46), and the universal LCI-LCIA matching polygons from $(47,48)$ were used to provide aggregated CFs in the SI.

The health impact data used in this work was obtained from (1) for five PM-related causes of mortality (chronic obstructive pulmonary disease, ischaemic heart disease, lower respiratory infections, lung cancer and stroke) at the age classes that were indicated in (10). The corresponding relative risk functions were taken from (10).

Global coal power PM impacts. To illustrate the application of our newly derived CFs, we combined them with a site-specific life cycle inventory (LCI) of global coal power generation and compared the results with the application of current alternative LCIA methodologies for primary and secondary particulate matter. These alternative methodologies were the aggregated global PM CFs from ReCiPe (3), the national CFs from LC-Impact (4), which represent an implementation of (2), and the archetypes from the UNEP-SETAC interim recommended methodology (6). In addition, a city-specific method for primary PM was applied by combining iFs (9) and EFs (10) as described in (49).

The emission inventory was obtained from (49). It includes the $\mathrm{PM}_{2.5}, \mathrm{SO}_{2}$ and $\mathrm{NO}_{\mathrm{x}}$ air emissions from global coal power generation in 2012. As different LCIA methods benefit from information on emission heights, we used coal power plant stack height data from (50) to derive the following correlation between generating unit capacity $C_{\text {unit }}$ in [MW] and stack height $h_{\text {stack }}$ in $[\mathrm{m}]$ from the fit of an exponential function:

$$
h_{\text {stack }}=16.249 \cdot C_{\text {unit }}^{0.3197}
$$

The relative standard deviation of reported heights from this correlation is $\pm 32.7 \%$. The correlation was used to approximate stack heights for every unit in the coal power emission data set. Subsequently, stack heights were used to interpolate linearly between the CFs of adjacent height classes.

\section{Results and discussion.}

Fate and effect. The simulation of atmospheric dispersion yielded the ground-level $\mathrm{PM}_{2.5}$ concentration changes. The Gaussian model that was selected is roughly accurate within a factor of two (13). While other model types have been reported to reach higher accuracies (Eulerian models for example $\pm 30-40 \%$ in (51)), this comes at the cost of substantially more computational time demands. This in turn would restrict the fate model to a certain region (as in (12)), limit its spatiotemporal resolution (as in (2)) or prescribe the calculation for a fixed set of archetypical conditions (as in (5)). Each of these alternatives would introduce additional spatio-temporal uncertainty. Considering the range of CFs (several orders of magnitude), an accuracy within a factor of two is acceptable. At the Gaussian model cut-off of $250 \mathrm{~km}$, on average $66 \%$ of primary $\mathrm{PM}_{2.5}, 62 \%$ of $\mathrm{SO}_{2}, 55 \%$ of $\mathrm{NO}_{\mathrm{x}}, 47 \%$ of $\mathrm{NH}_{3}$, including the respective reaction intermediates from ground-level emissions, were still contained in the air.

The calculated EFs showed strong dependence on $\mathrm{PM}_{2.5}$ background concentrations. Using a local distribution of $\mathrm{PM}_{2.5}$ levels led to less extreme EFs and hence more robust results compared to the use of one specific fixed local concentration over the entire year. This is of particular importance because EF curves for all three types (marginal, average, linear) of EFs tend to be very steep at $\mathrm{PM}_{2.5}$ background concentrations below $15 \mu \mathrm{g} \mathrm{m}^{-3}$, which are average background concentration levels for about half of the major global cities (9). In these cities, small model or measurement uncertainties as well as concentration fluctuations have a major influence on EFs. This issue is particularly apparent around the no-effect concentration, where a slightly lower average concentration can result in an EF of zero, while a slightly higher concentration results in the maximal EF.

The no-effect background concentration of $\mathrm{PM}_{2.5}$ results from the form of the mathematical expression that was fitted against cohort studies of PM exposure. Data at such low concentrations, however, is scarce and highly uncertain, while the mathematical fit expression was designed to include PM exposure levels far beyond background concentration levels (several orders of magnitude higher) (24). Such high exposure levels heavily influence the exact shape of exposure-response functions at low PM concentrations. Hence, we consider using a PM background concentration distribution a more robust choice than using one fixed background concentration. Nevertheless, the model behind the EFs is more uncertain than the fate model due to the complexity of human exposure-response and thus determines the overall uncertainty of this approach.

Characterization factor patterns. On average, the CFs fit well with earlier approaches while at the same time offering much higher spatial and temporal resolution. When comparing the ranges of CFs for the four substances, primary $\mathrm{PM}_{2.5}, \mathrm{SO}_{2}, \mathrm{NO}_{\mathrm{x}}$ and $\mathrm{NH}_{3}$, between LCIA methods, we see that our CFs generally fall into the same ranges, while overall having larger differences between minimal and maximal CFs (table 1). These ranges span more than four orders of magnitude for all precursor substances except $\mathrm{SO}_{2}$, where they span three orders of magnitude. 
Table 1. PM LCIA method comparison. CF ranges are given in [DALY/kg] (with a few extreme outliers having been removed).

\begin{tabular}{|c|c|c|c|c|c|}
\hline Method & This work & $\begin{array}{l}\text { Van Zelm et al. } 2008 \\
\text { (12) }\end{array}$ & $\begin{array}{l}\text { Van Zelm et al. } 2016 \\
\text { (2) }\end{array}$ & $\begin{array}{l}\text { UNEP-SETAC } 2016 \\
\text { (6) }\end{array}$ & $\begin{array}{l}\text { Fantke et al. } 2017 \\
(9), \quad \text { Fantke et al. } \\
2019 \text { (10) }\end{array}$ \\
\hline Fate model & $\begin{array}{l}\text { Gaussian }+ \text { long- } \\
\text { range compartment }\end{array}$ & $\begin{array}{l}\text { Gaussian }+ \text { long- } \\
\text { range Lagrangian }\end{array}$ & Eulerian & Multi-compartment & Multi-compartment \\
\hline Effect model & Non-linear & Linear & Linear & Linear & Non-linear \\
\hline Effect factor types & $\begin{array}{l}\text { Marginal, average, } \\
\text { linear }\end{array}$ & Average & Average & Marginal, average & Marginal, average \\
\hline Spatial resolution & $\begin{array}{l}0.25^{\circ} \times 0.25^{\circ} ; \text { global; } \\
\text { height classes }\end{array}$ & $\begin{array}{l}1^{\circ} \times 0.5^{\circ} ; \quad \text { Europe; } \\
\text { height classes }\end{array}$ & Country-level; global & $\begin{array}{l}\text { Unspecific (popu- } \\
\text { lation archetypes); } \\
\text { height classes (only } \\
\text { for } \mathrm{PM}_{2.5} \text { ) }\end{array}$ & $\begin{array}{l}3500 \text { cities; regions; } \\
\text { continents; height } \\
\text { classes }\end{array}$ \\
\hline Temporal resolution & Monthly; day/night & unspecific & unspecific & unspecific & unspecific \\
\hline Substances & $\begin{array}{l}\mathrm{PM}_{2.5}, \quad \mathrm{SO}_{2}, \quad \mathrm{NO}_{\mathrm{x}}, \\
\mathrm{NH}_{3}\end{array}$ & $\begin{array}{l}\mathrm{PM}_{10}, \quad \mathrm{SO}_{2}, \quad \mathrm{NO}_{\mathrm{x}}, \\
\mathrm{NH}_{3}\end{array}$ & $\begin{array}{l}\mathrm{PM}_{2.5}, \quad \mathrm{SO}_{2}, \quad \mathrm{NO}_{\mathrm{x}}, \\
\mathrm{NH}_{3}\end{array}$ & $\begin{array}{l}\mathrm{PM}_{2.5}, \quad \mathrm{SO}_{2}, \quad \mathrm{NO}_{\mathrm{x}}, \\
\mathrm{NH}_{3}\end{array}$ & $\mathrm{PM}_{2.5}$ \\
\hline $\mathrm{CF}$ range $\mathrm{PM}$ & $6 \mathrm{E}-7-2 \mathrm{E}-2$ & $5 \mathrm{E}-5-3 \mathrm{E}-4$ & $9 \mathrm{E}-6-4 \mathrm{E}-3$ & $1 \mathrm{E}-5-5 \mathrm{E}-3$ & $6 \mathrm{E}-7-9 \mathrm{E}-3$ \\
\hline $\mathrm{CF}$ range $\mathrm{SO}_{2}$ & $2 \mathrm{E}-7-5 \mathrm{E}-4$ & 5E-5 (mean) & $1 \mathrm{E}-5-1 \mathrm{E}-3$ & $7 \mathrm{E}-6-2 \mathrm{E}-4$ & $\mathrm{~N} / \mathrm{A}$ \\
\hline $\mathrm{CF}$ range $\mathrm{NO}_{\mathrm{x}}$ & $3 \mathrm{E}-8-8 \mathrm{E}-4$ & $6 \mathrm{E}-5$ (mean) & $4 \mathrm{E}-7-4 \mathrm{E}-4$ & $1 \mathrm{E}-6-3 \mathrm{E}-5$ & $\mathrm{~N} / \mathrm{A}$ \\
\hline $\mathrm{CF}$ range $\mathrm{NH}_{3}$ & $3 \mathrm{E}-7-5 \mathrm{E}-3$ & 8E-5 (mean) & $3 \mathrm{E}-6-1 \mathrm{E}-3$ & $1 \mathrm{E}-5-3 \mathrm{E}-4$ & $\mathrm{~N} / \mathrm{A}$ \\
\hline
\end{tabular}

The spatial CF patterns (figure 1) clearly show the relevance of local population densities for PM CFs. The highest CFs are invariably found close to densely populated areas like Northern India, Eastern China, Western Europe or in Indonesia around Jakarta. However, not every densely populated area automatically results in high CFs. This can be explained by very high background PM concentrations in some densely populated areas, which especially in the case of marginal effect models lead to low EF values.

Ground-level emissions lead to more extreme CFs than stack emissions. The pollutants stay closer to the source because of lower wind speeds at the ground, so local intake will be particularly high in the case of high local population density. Stack emissions, in comparison, distribute pollutants further and lead to local ground-level concentration maxima a few kilometers downwind of the emission source. Thus, we find regions at the edges of cities, where stack emissions, depending on the wind direction, have higher CFs than ground-level emissions.

Regional patterns for the four pollutants differ from each other substantially (figure 1). Primary $\mathrm{PM}_{2.5} \mathrm{CF}$ patterns show more isolated $\mathrm{CF}$ peaks compared to $\mathrm{SO}_{2}, \mathrm{NO}_{\mathrm{x}}$ and $\mathrm{NH}_{3}$. The latter three substances are $\mathrm{PM}_{2.5}$ precursors and their chemical reaction delays $\mathrm{PM}_{2.5}$ formation so that the particles are more distributed and local population differences become less influential for the CFs.

In the case of the highest CFs for primary $\mathrm{PM}_{2.5}$, we observe general overlap between our work and the trends found by van Zelm and co-workers (2): India, China, Egypt, Western Europe and Japan are identified as hotspot regions by both methods. We, however, also find very high CFs for primary $\mathrm{PM}_{2.5}$ in Indonesia, the Philippines, the US and Russia, which is supported by the city-specific approach of $(9,10)$. The lower values of van Zelm for the latter regions could be due to a lack of spatial resolution that would differentiate between the large population density differences in these regions.

We calculate the lowest global CFs for primary $\mathrm{PM}_{2.5}$ in the largely uninhabited rainforest areas of South America and Oceania. There, a small amount of potentially affected humans coincides with large amounts of rainfall that wash the particles out of the air.

CFs for $\mathrm{SO}_{2}$ show a similar pattern compared to primary
$\mathrm{PM}_{2.5}$ CFs. Hotspots often overlap, but the $\mathrm{SO}_{2} \mathrm{CFs}$ are more evenly distributed than $\mathrm{PM}_{2.5} \mathrm{CFs}$. The cause for that is the atmospheric chemistry of $\mathrm{SO}_{2}$, which results in a smaller spread between minimal and maximal $\mathrm{SO}_{2} \mathrm{CFs}$, and allows for more dry and wet deposition before transformation to $\mathrm{PM}_{2.5}$. The seasonal variation of $\mathrm{SO}_{2} \mathrm{CFs}$ is lower than in case of primary $\mathrm{PM}_{2.5}$ because the washout rate of $\mathrm{SO}_{2}$ during rain or snowfall is lower than for primary $\mathrm{PM}_{2.5}$ (17). Thus, both location and time of emission matter less than for primary $\mathrm{PM}_{2.5}$. The hotspot regions for $\mathrm{SO}_{2} \mathrm{CFs}$ are mostly found in Western Europe, Indonesia, India, China, Japan and Egypt. Of particular concern are the high $\mathrm{SO}_{2} \mathrm{CFs}$ in some of the worlds largest port cities (Shanghai, Shenzhen, Rotterdam, Antwerp, New York) and along major shipping routes (English Channel, Suez Canal, Strait of Gibraltar), as both freight and cruise ships are among the largest $\mathrm{SO}_{2}$ emitters globally.

The $\mathrm{NO}_{\mathrm{x}} \mathrm{CF}$ pattern is different from primary $\mathrm{PM}_{2.5}$ and $\mathrm{SO}_{2}$ because of the particular $\mathrm{NO}_{\mathrm{x}}$ chemistry. The chemical equilibrium between the reaction intermediate $\mathrm{HNO}_{3}$ and $\mathrm{NH}_{3}$ that forms particulate $\mathrm{NH}_{4} \mathrm{NO}_{3}$ depends on weather conditions such as humidity, temperature and background concentrations (19) and thus shows high spatial and temporal variability. Seasonally cold temperatures and high humidity shift the equilibrium from $\mathrm{HNO}_{3}$ and $\mathrm{NH}_{3}$ to $\mathrm{NH}_{4} \mathrm{NO}_{3}$. Thus, CFs may be high unless there is heavy rainfall that washes out $\mathrm{HNO}_{3}$ in particular and thus lowers the CFs. Dry and hot conditions, on the other hand, are often associated with high ozone concentrations and more solar radiation, which both lead to faster formation of $\mathrm{HNO}_{3}$ from $\mathrm{NO}_{\mathrm{x}}$. In combination with high $\mathrm{NH}_{3}$ levels at warm conditions, $\mathrm{PM}_{2.5}$ formation from $\mathrm{NO}_{\mathrm{x}}$ may be substantial despite a shift of the chemical equilibrium towards the educts. In consequence, both summer and winter can be very problematic for $\mathrm{PM}_{2.5}$ impacts from $\mathrm{NO}_{\mathrm{x}}$, while spring and autumn with moderate temperatures and higher levels of rainfall are often of less concern. Key regions with very high $\mathrm{NO}_{\mathrm{x}} \mathrm{CFs}$ are Europe and Indonesia, and to a lesser extent also Japan and China. India also has high CFs from $\mathrm{NO}_{\mathrm{x}}$ in summer. Other temporal issues become apparent in January around Rio de Janeiro and New York City, and in April in Colombia and Kenya.

$\mathrm{CF}$ patterns for $\mathrm{NH}_{3}$ are similar to $\mathrm{NO}_{\mathrm{x}} \mathrm{CF}$ patterns since they share parts of the same chemical reaction pathway to 

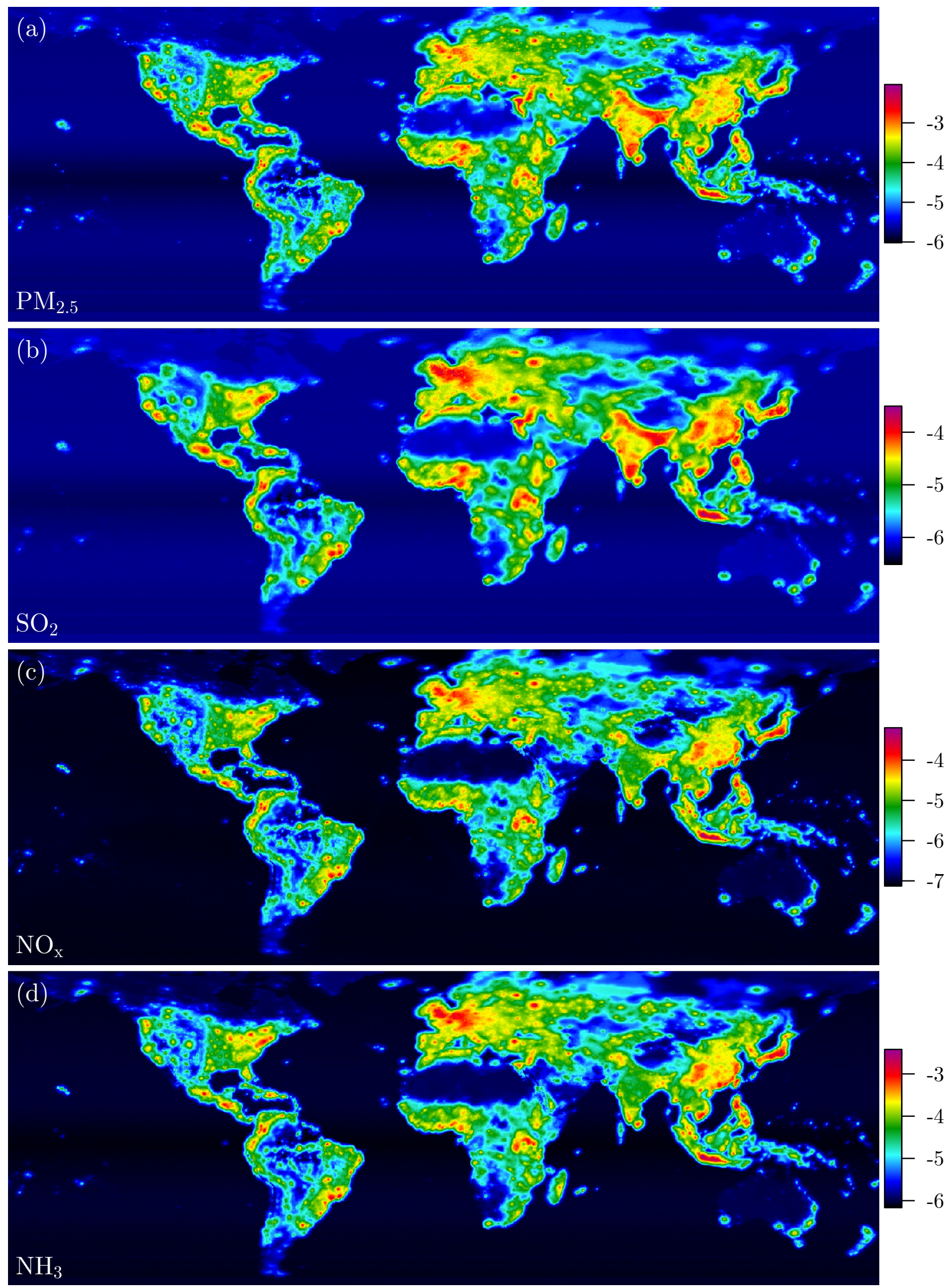

Figure 1. PM health impact CF maps (logarithmic scale, annual average CFs, emission height ground-level, marginal EFs). Primary pollutants are (a) $\mathrm{PM}_{2.5}$, (b) $\mathrm{SO}_{2}$, (c) $\mathrm{NO}_{x}$, and (d) $\mathrm{NH}_{3}$. CFs are expressed in [DALY/kg]. 
secondary $\mathrm{PM}_{2.5}$ formation. $\mathrm{NH}_{3}$ emissions are most problematic in Europe, followed by China and Japan. The CF distribution within Europe is in good agreement with the Europe-specific study of (12). Furthermore, CFs are locally high around around Jakarta and New York City. The seasonal patterns of $\mathrm{NH}_{3}$ are closely related to the background pollution. Secondary $\mathrm{PM}_{2.5}$ formation from $\mathrm{NH}_{3}$ at cold temperatures and low background $\mathrm{NH}_{3}$ levels is limited by $\mathrm{NH}_{3}$ availability (19), which means that any additional $\mathrm{NH}_{3}$ emissions directly translate into additional $\mathrm{PM}_{2.5}$ formation. Hence, CFs for cold weather and low $\mathrm{NH}_{3}$ concentrations during winter results in high $\mathrm{NH}_{3} \mathrm{CFs}$ in both Europe and North America. Humidity has also been observed to influence concentrations, but to a smaller degree than the influence of background concentrations and temperature.

Coal power health impacts. Health benefits from the potential decrease of coal power emissions differ widely when using different current PM LCIA methods and there is major disagreement of what key issues should be addressed with highest priority. First, the total PM-related health impact results based on each of the LCIA methods are very different from each other. Using the global ReCiPe CFs, for example, leads to $\mathrm{PM}_{2.5}$ coal power impacts of $5.8 \mathrm{M} \mathrm{DALY} \mathrm{a}^{-1}$, while the regionalized method of (2) calculates impacts that are twice as high (10.4 $\left.\mathrm{M} \mathrm{DALY} \mathrm{a}^{-1}\right)$. The archetype approach from (6) results in much lower impacts of about $1.1 \mathrm{M} \mathrm{DALY}^{-1}$, which is in rough agreement with the $0.08 \mathrm{M} \mathrm{DALY} \mathrm{a}^{-1}$ calculated with $(9,10)$ for primary $\mathrm{PM}_{2.5}$ only. Our own calculations result in lower total impacts of $0.4 \mathrm{MDALY} \mathrm{a}^{-1}$, of which $0.08 \mathrm{M} \mathrm{DALY} \mathrm{a}^{-1}$ come from primary $\mathrm{PM}_{2.5}$, and thus fit better with the archetype approach rather than the regionalized or global approaches.

The reason for these large discrepancies between each of the LCIA methods lies in their simplifications. The global approach, for example, allows for a rough order-of-magnitude estimate of PM health impacts, including a comparison of the relevant precursor substances. However, when different emission characteristics come into play at the same time (such as stack and ground-level emissions, or different emission locations), comparisons of emission sources are misleading where differences of key characteristics with high influence on the results are not distinguished.

For $\mathrm{SO}_{2}$ and $\mathrm{NO}_{\mathrm{x}}$ emissions, stack heights are not explicitly differentiated by CFs from either of the established methods. The different total impact amounts instead arise from the different order of magnitude in CFs, which are the result of specific assumptions in each model. The most important assumptions include the EF model and the specific environmental properties. By neglecting stack heights, the CFs for $\mathrm{SO}_{2}$ and $\mathrm{NO}_{\mathrm{x}}$ stack emissions in the established methods are comparably conservative.

Lower overall impacts from our CFs compared to the other methods are explained by the high resolution of our approach in India and China, where a major fraction of PM-related emissions meets low EFs despite high population densities. Ultimately, the overall health impacts from each approach reflect how they treat this specific situation. As the global CFs from (3) do not distinguish specific local conditions, their impacts are proportional to the emissions irrespective of source region, which is why impacts are largely located outside of India and China. The regionalized approach from (2) finds
$60 \%$ of impacts originating from India are due to high population density and its correlation with emission source locations. India is also responsible for a large share of impacts in the case of (6), but China has the highest impacts since differences in population densities, background pollution and weather conditions between urban areas in China and India are not further distinguished. The city-specific approach of $(9,10)$ also shows the general pattern of (6) despite being limited to primary $\mathrm{PM}_{2.5}$, which can be explained by the same shared conceptual framework and the population densities being ultimately the most decisive parameter in these two approaches. Our own work offers a more in-depth view due to increased resolution. It shows an even distribution of impacts between India (very polluting plants), China (many plants) and other regions like Europe (combination of both factors in addition to high local CFs).

We observe little correlation among methods when comparing the impacts for each power plant. This is despite the large differences in absolute plant emissions, which cover a range of several orders of magnitude from the lowest to the highest value and therefore increase the correlation of impacts. From a comparison of the primary $\mathrm{PM}_{2.5}$ impacts of the two approaches with the highest spatial resolutions, the city-specific approach from Fantke $(9,10)$ and our own calculations, we calculate a Pearson correlation co-efficient that is lower than that between our approach and the regionalized impacts with (2) $(r=0.40$ and $r=0.65$, respectively). This low correlation is surprising as both our and the city-specific approach $(9,10)$ use non-linear EF models and local population densities that are decisive parameters with a major influence on the results, while the other approaches are less detailed in this regard. Reasons for the discrepancies are therefore more likely to be found in other parts of the respective models. Here, the most notable difference between the approach from $(9,10)$ and ours is that the former are using fixed background concentrations for determining local EFs while we use distributed concentration data. CFs are very sensitive towards fixed PM background concentrations because EF curves are steep at common background PM levels. Furthermore, they have developed their approach for ground-level emissions. Other emission heights are then calculated by multiplication with fixed source factors that scale the pollutant intake down. This, however, might be an oversimplification for stack emissions as their distribution patterns differ from those of ground-level emissions.

An analysis of $\mathrm{PM}_{2.5}$-related health impacts for each coal power plant from (49) in combination with our highly regionalized $\mathrm{CF}$ model demonstrates how difficult it is to derive general patterns due to the complexity of conditions at different plants. Thus, we find numerous units where either $\mathrm{SO}_{2}$, $\mathrm{NO}_{\mathrm{x}}$ or primary $\mathrm{PM}_{2.5}$ can be the main cause of the health impacts (figure 2). Also, the plant size and the amount of electricity produced are only partly indicative of impacts as small plants may have low stacks, less sophisticated flue gas treatment and are more frequently located in cities, which may increase both total emissions and impacts per amount of electricity produced. In addition, we only observe a loose correlation between population densities and health impact changes due to emission changes because of the non-linear $\mathrm{EF}$ model and the weather influence for $\mathrm{PM}_{2.5}$ formation and transport.

Globally, most coal power plants are located above the equa- 

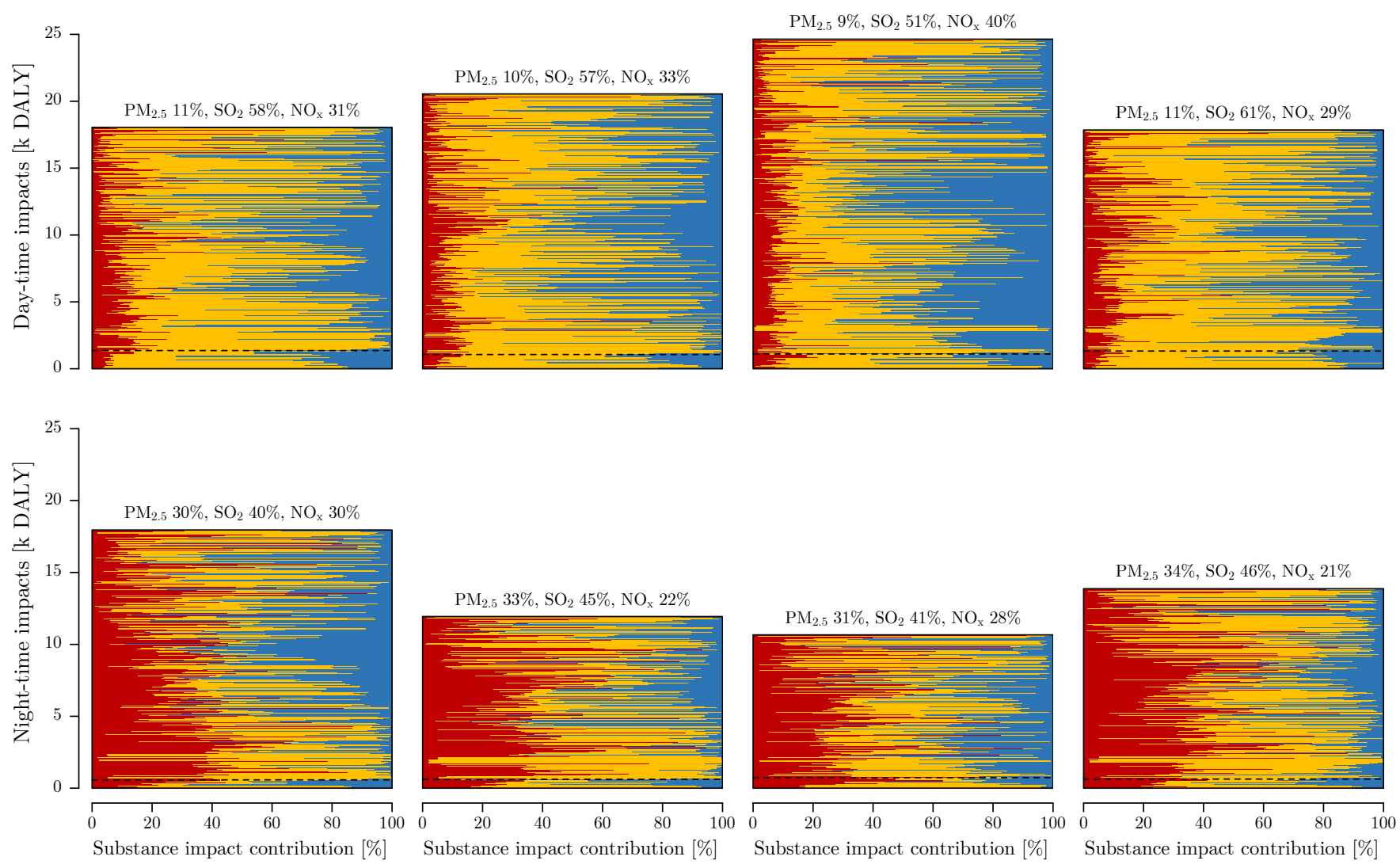

Figure 2. Daytime and nighttime PM $M_{2.5}$ health impact reduction potentials from coal power generation per generating unit during different months of the year (LCIA method from this work, marginal CFs). Each line represents a single generating unit with its health impact distribution per emitted substance shown on the $x$-axis and its width in $y$-direction indicating its PM-related health impacts. Generating units are sorted geographically from highest (top) to lowest (bottom) latitude. The dashed lines mark the equator. Coal power generation is not a major source of $\mathrm{NH}_{3}$ emissions so their impacts have not been quantified.

tor. Hence, the seasonal pattern in the northern hemisphere is most decisive for pollution impacts from coal power generation. Primary $\mathrm{PM}_{2.5}$ health impacts are higher during the nighttime (irrespective of month) as lower temperatures tend to keep the plumes lower to the ground, increase ground-level concentrations and thus lead to higher health impacts. $\mathrm{NO}_{\mathrm{x}}$ health impacts are highest during summer and winter. Winter is especially problematic in North America, Europe and China, while summer is more problematic in India. Especially cold winter nights contribute to high $\mathrm{NO}_{\mathrm{x}}$ health impacts. $\mathrm{SO}_{2}$ emissions play a key role for coal power health impacts in all regions and at all times throughout the year, but its contribution during nighttime is considerably lower than during daytime because nighttime reaction kinetics are slower.

From a comparison of potential health impact reductions calculated with marginal and average effect factors we can see in which way potential health benefits change if they are part of larger efforts to reduce $\mathrm{PM}_{2.5}$ pollution within a region (supplementary figure 8). Generally, these benefits stay within a range of $\pm 20 \%$ and thus do not change substantially for most places. There are, however, also several larger regions (India and China) and some regional hotspots (for example in South Africa or Russia), where average health benefits from reducing emissions exceed marginal health benefits by $100 \%$ or more. These places have a high background $\mathrm{PM}_{2.5}$ pollution in common, which causes major differences between $\mathrm{CF}$ types as these concentrations correspond to the comparably flat part of the dose-response curves (24). Thus, the health benefits from small marginal emission decreases in these regions are much lower than for larger emission decreases per amount of pollutant. China and India are highly attractive targets for decreasing global $\mathrm{PM}_{2.5}$ health burdens due to the disproportionately strong health benefits at larger emission reductions.

Uncertainty and variability. Uncertainties in this work are difficult to quantify as they depend on a multitude of aspects including input data and model assumptions. In general, the concentrations from Gaussian atmospheric dispersion models are roughly accurate within a factor of 2 according to (52). Uncertainties are lower close to the emission source and increase further away. We observe the highest CFs where the peaks of ground-level concentrations coincide with densely populated areas. These concentration peaks are typically found within a few kilometers downwind of the emission source where the dispersion model is most accurate. In addition, exact concentration levels are less relevant further away from the emission source because the cone of the plume becomes larger and the 
impacts become more distributed. Thus, the large differences in the number of exposed people downwind of the emission source is more influential on the CFs than the concentration levels with their relatively small uncertainty.

The uncertainty of EFs directly depends on the uncertainty of the risk ratios, which is in the range of $\pm 10-40 \%$ (24). Fantke and co-workers (10) use such data and find median marginal EF uncertainty ranges of $-21 \%$ to $+24 \%$. Additional uncertainty comes from the assumed background pollutant concentrations as these determine the local EFs. Using a distribution of background concentrations from measurements reduces uncertainties, but since such measurement data is not universally available at high spatial and temporal resolution, we cannot quantify it on the global scale. The same applies to the uncertainties from all other input data.

The variability over the year depends largely on the local atmospheric conditions. An example calculation for groundlevel emissions in Jakarta has been performed with a marginal EF model and results in high relative standard deviations of $\pm 320 \%$ for $\mathrm{PM}_{2.5}, \pm 230 \%$ for $\mathrm{SO}_{2}, \pm 280 \%$ for $\mathrm{NO}_{\mathrm{x}}$, and $\pm 230 \%$ for $\mathrm{NH}_{3}$ CFs over the year. The spatial variability within Indonesia, for comparison, is $\pm 180 \%$ for $\mathrm{PM}_{2.5}, \pm 150 \%$ for $\mathrm{SO}_{2}, \pm 210 \%$ for $\mathrm{NO}_{\mathrm{x}}$, and $\pm 210 \%$ for $\mathrm{NH}_{3}$ (for other countries, see supplementary table 13). Such ranges are in good agreement with relative standard deviations of measured $\mathrm{PM}_{2.5}$ levels in Jakarta of $\pm 300 \%$ (53).

While uncertainty of the results needs to be considered, we have compared the potential overall health impact improvements of the coal power study to the total ambient PM health impacts from (1), which indicate that our results are meaningful considering the limited applicability of linearized LCIA CFs for assessing total impacts (as described in more detail in the SI).

Limitations and outlook. The limitations of the present work mostly arise from the inherent limitations of the Gaussian fate model (as discussed for example in (13)). It draws its fast performance from assuming a steady state of weather conditions. Thus, some chemical reaction pathways and weather effects were simplified. In addition, there may be cases where the model cut-off at $250 \mathrm{~km}$ leads to the underestimation of $\mathrm{CFs}$, even though such a radius typically allows to model more than $80 \%$ of the health impacts from primary and secondary $\mathrm{PM}_{2.5}$ in detail (54). With more computational resources, the cut-off could be extended and a long-range Lagrangian or Eulerian model could be added $(12,13)$. Direct sampling from global high-resolution atmospheric data (such as hourly gridded wind data) would allow to provide a more detailed picture of environmental conditions. Further improvements would be possible by including more realistic exposure patterns and by quantifying uncertainties comprehensively. The contributions of various organic compounds to $\mathrm{PM}_{2.5}$ health impacts and toxicity differences between different kinds of PM currently lack data and therefore could not be included.

With our work, we were able to demonstrate that spatiotemporal patterns are decisive for the assessment of health impacts from particulate matter, and that a lack of resolution may heavily alter the conclusions of LCA studies. In consequence, future work should increase the resolution of background LCI databases accordingly, develop LCA software that supports the use of high-resolution data and - as the bare minimum - report on the major uncertainties in case no spatio-temporal information is available.

Acknowledgments. We thank Christie Walker for proofreading our manuscript, Mark Huijbregts, Peter Fantke and Till Bachmann for providing invaluable feedback on our approach, Thomas Sonderegger for advice on regional aggregation of characterization factors, as well as Jack Hensley, Helen DrozGeorget, Musuizi Lei and Christian Egli for their contributions to the early development stages of this work. Furthermore, we gratefully acknowledge partial funding by Innosuisse and SCCER-Mobility.

Author contributions. $\mathrm{CO}, \mathrm{SP}$ and $\mathrm{SH}$ designed the research; $\mathrm{CO}$ collected the data and did the modeling with contributions from SP; CO and SP interpreted the results; CO wrote the paper with inputs from SP and SH.

Competing interests. We declare no competing interests.

Supporting materials. Extended descriptions of methods and additional results including aggregated CFs for countries, provinces, ecoinvent regions, universal LCI-LCIA matching polygons from $(47,48)$, and the world are available in the SI. Case study data, source code for the model (R v3.6.0) (55), and characterization factor maps are available from http://dx.doi.org/10.17632/8jnj4vzbh6.1 (56). The case study data is fully compatible with the power plant data sets from $(49,57-60)$.

Correspondence. Please contact the authors directly at oberschelp@ifu.baug.ethz.ch for specific questions or data requests.

\section{References}

1. GBD 2017 DALYS and HALE Collaborators. Measuring progress from 1990 to 2017 and projecting attainment to 2030 of the health-related Sustainable Development Goals for 195 countries and territories - a systematic analysis for the Global Burden of Disease Study 2017. The Lancet, 392(10159):2091-2138, November 2018.

2. $R$ van Zelm, $P$ Preiss, $T$ van Goethem, $R$ van Dingenen, and $M$ Huijbregts. Regionalized life cycle impact assessment of air pollution on the global scale: Damage to human health and vegetation. Atm Env, 134:129-137, June 2016.

3. M Huijbregts, Z Steinmann, P Elshout, G Stam, F Verones, M Vieira, A Hollander, $M$ Zijp, and $R$ van Zelm. ReCiPe 2016: A harmonized life cycle impact assessment method at midpoint and endpoint level - Report I: Characterization. Bilthoven, NL, 2016. https://www.rivm.nl/en/Documents_and_publications/Scientific/Reports/2016/december/ ReCiPe_2016_A_harmonized_life_cycle_impact_assessment_method_at_midpoint_and_ endpoint_level_Report_I_Characterization. Retrieved on 2018-01-11.

4. F Verones, S Hellweg, L Azevedo, A Chaudhary, N Cosme, P Fantke, M Goedkoop, M Hauschild, A Laurent, C Mutel, S Pfister, T Ponsioen, Z Steinmann, R van Zelm, M Vieira, and M Huijbregts. LC-Impact Version 0.5, 2016. Characterization factor maps available at http://lc-impact.eu/downloads-characterisation-factors. Retrieved on 2018-07-20.

5. S Humbert, J D Marshall, S Shaked, JV Spadaro, Y Nishioka, P Preiss, TE McKone, A Horvath, and $O$ Jolliet. Intake fraction for particulate matter: recommendations for life cycle impact assessment. Environ Sci Technol, 45(11):4808-4816, 2011.

6. P Fantke, J Evans, N Hodas, J Apte, M Jantunen, O Jolliet, and TE McKone. Global Guidance for Life Cycle Impact Assessment Indicators - Volume 1, chapter Health impacts of fine particulate matter, pages 76-99. United Nations Environment Programme (UNEP), 2016.

7. C Bulle, M Margni, L Patouillard, AM Boulay, G Bourgault, V De Bruille, V Cao, M Hauschild, A Henderson, S Humbert, S Kashef-Haghighi, A Kounina, A Laurent, A Levasseur, G Liard, RK Rosenbaum, PO Roy, S Shaked, P Fantke, and O Jolliet. IMPACT World+: a globally regionalized life cycle impact assessment method. Int J LCA, pages 1-22, February 2019.

8. JS Apte, E Bombrun, JD Marshall, and WW Nazaroff. Global Intraurban Intake Fractions for Primary Air Pollutants from Vehicles and Other Distributed Sources. Environ Sci Technol, 46(6):3415-3423, 2012.

9. P Fantke, O Jolliet, J Apte, N Hodas, J Evans, C Weschler, K Stylianou, M Jantunen, and T McKone. Characterizing Aggregated Exposure to Primary Particulate Matter: Recommended Intake Fractions for Indoor and Outdoor Sources. Environ Sci Technol, 51(16):90899100, 2017.

10. P Fantke, TE McKone, M Tainio, O Jolliet, JS Apte, KS Stylianou, N IIIner, JD Marshall, EF Choma, and JS Evans. Global Effect Factors for Exposure to Fine Particulate Matter. Environ Sci Technol, 53(12):6855-6868, 2019.

11. CA Pope III, RT Burnett, MJ Thun, EE Calle, D Krewski, K Ito, and GD Thurston. Lung Cancer, Cardiopulmonary Mortality, and Long-term Exposure to Fine Particulate Air Pollution. JAMA, 287(9):1132-1141, 2002. 
12. R van Zelm, MAJ Huijbregts, HA den Hollander, HA Van Jaarsveld, FJ Sauter, J Struijs, HJ van Wijnen, and D van de Meent. European characterization factors for human health damage of PM10 and ozone in life cycle impact assessment. Atm Env, 42(3):441-453, 2008.

13. CM Bhumralkar and RE Ruff. The Acid Deposition Phenomenon and its Effects - Longrange Transport and Acidic Deposition Models. In The Acidic Deposition Phenomenon and Its Effects: Critical Assessment Papers, Volume 1. US Environmental Protection Agency (EPA), 1984.

14. US Environmental Protection Agency (EPA). Users guide to the Industrial Source Complex (ISC3) dispersion models - Volume II - Description of model algorithms, 1995. Available online at https://www3.epa.gov/scram001/userg/regmod/isc3v2.pdf. Accessed on 2019-03-23.

15. Cambridge Environmental Research Consultants. ADMS5 Atmospheric Dispersion Modelling System User Guide, 2016. Available online at http://www.cerc.co.uk/environmental-software/ user-guides.html. Accessed on 2019-03-19.

16. D Wen, JC Lin, L Zhang, R Vet, and MD Moran. Modeling atmospheric ammonia and ammo nium using a stochastic Lagrangian air quality model (STILT-Chem v0.7). Geosci Model Dev 6(2):327-344, 2013

17. JS Scire, DG Strimaitis, and RJ Yamartino. A Users Guide for the CALPUFF Disper sion Model. Concord, MA, 2000. Available online at http://www.src.com/calpuff/download/ CALPUFF_UsersGuide.pdf. Accessed on 2019-04-26.

18. J Bartnicki, K Olendrzynski, JE Jonson, E Berge, and S Unger. Description of the Eulerian Acid Deposition Model, 2002. Available online at https://www.emep.int/mscw/eudm_acid model.pdf. Accessed on 2019-06-12.

19. M Mozurkewich. The dissociation constant of ammonium nitrate and its dependence on temperature, relative humidity and particle size. Atmospheric Environment. Part A. General Topics, 27(2):261-270, 1993.

20. Cambridge Environmental Research Consultants. ADMS-Roads - Air Quality Management System Version 4.1 - User Guide, 2017. Available online at http://www.cerc.co.uk environmental-software/user-guides.html. Accessed on 2019-03-22.

21. The World Bank Group. Population, total, 2019. Available online at https://data.worldbank. org/indicator/SP.POP.TOTL?view=chart. Accessed on 2019-07-26.

22. HAU de Haes, O Jolliet, G Finnveden, M Hauschild, W Krewitt, and R Müller-Wenk. Best available practice regarding impact categories and category indicators in life cycle impact assessment. Int J LCA, 4(2):66, 1999.

23. MAJ Huijbregts, $S$ Hellweg, and $E$ Hertwich. Do we need a paradigm shift in life cycle impact assessment? Environ Sci Technol, 45(9):3833-3834, 2011.

24. R Burnett, A Pope III, M Ezzati, C Olives, S Lim, S Mehta, H Shin, G Singh, B Hubbell, $\mathrm{M}$ Brauer, $\mathrm{H}$ Anderson, $\mathrm{K}$ Smith, J Balmes, $\mathrm{N}$ Bruce, $\mathrm{H}$ Kan, $\mathrm{F}$ Laden, A Pruss-Ustun, M Turner, S Gapstur, R Diver, and A Cohen. An Integrated Risk Function for Estimating the Global Burden of Disease Attributable to Ambient Fine Particulate Matter Exposure. Environ Health Perspect, 122(4):397-403, April 2014.

25. SE Fick and RJ Hijmans. WorldClim 2: new 1-km spatial resolution climate surfaces for global land areas. Int J Clim, 37(12):4302-4315, 2017.

26. M New, M Hulme, and $P$ Jones. Representing twentieth-century space-time climate variability. Part I: Development of a 1961-90 mean monthly terrestrial climatology. J Clim, 12(3):829-856, 1999. Map available online at https://nelson.wisc.edu/sage/data-and-models/ atlas $/$ maps.php?datasetid $=53$ \&includerelatedlinks $=1$ \&dataset $=53$. Accessed on 2019-05-17 Used by permission of The Center for Sustainability and the Global Environment, Nelson Institute for Environmental Studies, University of Wisconsin-Madison.

27. R Stockli. Cloud Fraction (1 month - Terra/MODIS) data 2015, 2019. Available online at https://neo.sci.gsfc.nasa.gov/view.php?datasetld=MODAL2_M_CLD_FR\& date $=2015-01-01$. Accessed on 2019-05-03.

28. TD Mitchell and PD Jones. An improved method of constructing a database of monthly climate observations and associated high-resolution grids. Int J Clim, 25(6):693-712, 2005.

29. Technical University of Denmark (DTU)/ World Bank Group. Global Wind Atlas 2.0, 2018 Available online at https://globalwindatlas.info. Accessed on 2018-05-08 and 2019-06-12.

30. A Van Donkelaar, RV Martin, M Brauer, NC Hsu, RA Kahn, RC Levy, A Lyapustin, AM Sayer, and DM Winker. Global estimates of fine particulate matter using a combined geophysicalstatistical method with information from satellites, models, and monitors. Environ Sci Technol, 50(7):3762-3772, 2016.

31. K Miyazaki, HJ Eskes, and K Sudo. A tropospheric chemistry reanalysis for the years 20052012 based on an assimilation of OMI, MLS, TES, and MOPITT satellite data. Atm Chem Phys, 15(14):8315-8348, 2015.

32. K Miyazaki, HJ Eskes, and K Sudo. A tropospheric chemistry reanalysis for the years 20052014 based on an assimilation of OMI, MLS, TES, and MOPITT satellite data, 2015. American Geophysical Union, Fall Meeting 2015. Data available from https://ebcrpa.jamstec.go.jp/ miyazaki/tcr/. Accessed on 2019-09-12.

33. JX Warner, Z Wei, LL Strow, RR Dickerson, and JB Nowak. The global tropospheric ammonia distribution as seen in the 13-year AIRS measurement record. Atm Chem Phys, 16(8):54675479, 2016.

34. UK Department for Environment Food \& Rural Affairs (DEFRA). Air Information Resource, 2019. Data available from https://uk-air.defra.gov.uk/networks/find-sites. Accessed on 2019 09-04.

35. US Environmental Protection Agency (EPA). EPA Air Data - Pre-Generated data files - Hourly data for criteria gases, particulates and meteorological conditions, 2019. Data available from https://aqs.epa.gov/aqsweb/airdata/download_files.html\#Raw. Accessed on 2019-09-04.

36. Norwegian Institute for Air Research (NILU). EBAS database, 2019. Data available from http://ebas.nilu.no. Accessed on 2019-09-04.

37. U.S. Department of State. U.S. Department of State Air Quality Monitoring Program - Mission China, 2019. Data available from http://stateair.net/web/historical/. Accessed on 2019-09-04.

38. NSW Department of Planning, Industry and Environment, Environment, Energy and Science (EES) Group. Office of Environment and Heritage (OEH) Air Program data, 2019. Data available from https://www.environment.nsw.gov.au/aqms/search.htm. Accessed on 2019-0722.

39. BC Ministry of Environment. BC Air Data Archive, 2019. Data available from https: /envistaweb.env.gov.bc.ca/. Accessed on 2019-07-22.

40. Central Pollution Control Board (CPCB) - Government of India. Continuous Ambient Air Quality Monitoring (CAAQM) data, 2019. Data available from https://app.cpcbccr.com/ccr/. Accessed on 2019-07-23.

41. Ministry of Environment and Urbanisation, Measurement and Monitoring Office, Environment Reference Laboratory. Air quality data, 2019. Data available from http://www.havaizleme.gov. tr. Accessed on 2019-07-22.

42. Landesamt für Natur, Umwelt und Verbraucherschutz Nordrhein-Westfalen (LANUV). Messorte der Luftqualitätsüberwachung in NRW, 2019. Available online at https://www.lanuv.nrw. de/umwelt/luft/immissionen/messorte-und-werte. Accessed on 2019-07-22.

43. Socioeconomic Data and Applications Center (SEDAC). Gridded Population of the World GPW), v4.10, 2016. Data available online at http://beta.sedac.ciesin.columbia.edu/data/set/ gpw-v4-population-density/data-download. Accessed on 2016-05-19.

44. Natural Earth Data. Admin 0 - Countries v4.1.0; Admin 1 - States, Provinces v4.1.0; Urban Areas v4.0.0, 2019. Available online at http://www.naturalearthdata.com/. Accessed on 201908-07.

45. The ecoinvent Association. Ecoinvent geography definitions v2.3, 2019. Available online at https://geography.ecoinvent.org/\#data-formats. Accessed on 2019-08-07.

46. The ecoinvent Association. Ecoinvent geography definitions v2.4, 2020. Available online at https://geography.ecoinvent.org/\#data-formats. Accessed on 2020-10-19.

47. S Pfister, C Oberschelp, and T Sonderegger. Regionalized LCA in practice: the need for a universal shapefile to match LCI and LCIA. Int J LCA, 25:1867-1871, 2020

48. T Sonderegger, S Pfister, and Oberschelp C. Layer for regionalized LCA data (LCl) and characterization factors (LCIA), Version 2, 2020. Mendeley Data. Available online at http: //dx.doi.org/10.17632/8zxc3kzwxj.2.

49. C Oberschelp, S Pfister, CE Raptis, and S Hellweg. Global emission hotspots of coal power generation. Nature Sustainability, 2(2):113, 2019.

50. National Energy Technology Laboratory (NETL). Coal Power Plant Database (CPPDB) 2005, 2007. Retrieved on 2015-09-30.

51. M Prank, M Sofiev, S Tsyro, C. Hendriks, V Semeena, X Vazhappilly Francis, T Butler, H Denier van der Gon, R Friedrich, J Hendricks, X Kong, M Lawrence, M Righi, Z Samaras, $R$ Sausen, J Kukkonen, and R Sokhi. Evaluation of the performance of four chemical transport models in predicting the aerosol chemical composition in Europe in 2005. Atmos Chem Phys, 16(10):6041-6070, 2016.

52. K Massmeyer, H Geiss, K Heinemann, M Möllmann, and G Polster. Atmospheric dispersion around an isolated hill - programme and preliminary results. In Air Pollution Modeling and lts Application V, pages 581-590. Springer, 1986.

53. U.S. Department of State - U.S. Embassy and Consulates in Indonesia. U.S. Embassy Jakarta Air Quality Monitor, 2019. Data available from https://id.usembassy.gov/ embassy-consulates/airqualitymonitor/. Accessed on 2019-10-26.

54. AL Goodkind, CW Tessum, JS Coggins, JD Hill, and JD Marshall. Fine-scale damage estimates of particulate matter air pollution reveal opportunities for location-specific mitigation of emissions. PNAS, 116(18):8775-8780, 2019.

55. R Core Team. R: A Language and Environment for Statistical Computing. Vienna, Austria, 2019.

56. C Oberschelp, S Pfister, and S Hellweg. Global particulate matter life cycle impact assessment maps, 2020. Mendeley Data. Available online at http://dx.doi.org/10.17632/8jnj4vzbh6.

57. C. E. Raptis and S. Pfister. Global freshwater thermal emissions from steam-electric power plants with once-through cooling systems. Energy, 97:46-57, 2016.

58. C. Oberschelp, S. Pfister, C. E. Raptis, and S. Hellweg. Global coal power plant airborne emission dataset, 2019. Mendeley Data. Available online at http://dx.doi.org/10.17632/ dm3rib9ymc.1.

59. CE Raptis, C Oberschelp, and S Pfister. The greenhouse gas emissions, water consumption, and heat emissions of global steam-electric power production: a generating unit level analysis and database. Env Res Lett, 15(10), 2020.

60. Platts. World Electric Power Plants Database (WEPP), March 2012, 2012. 